\title{
Ceilometer aerosol profiling versus Raman lidar in the frame of the INTERACT campaign of ACTRIS
}

\author{
F. Madonna ${ }^{1}$, F. Amato ${ }^{1}$, J. Vande $\mathrm{Hey}^{2}$, and G. Pappalardo ${ }^{1}$ \\ ${ }^{1}$ Istituto di Metodologie per l'Analisi Ambientale (CNR-IMAA),Consiglio Nazionale delle Ricerche, \\ C. da S. Loja - Zona Industriale, 85050 Tito Scalo, Potenza, Italy \\ ${ }^{2}$ Department of Physics and Astronomy, Earth Observation Science Group, University of Leicester, University Road, \\ Leicester, LE1 7RH, UK \\ Correspondence to: F. Madonna (fabio.madonna@imaa.cnr.it)
}

Received: 16 October 2014 - Published in Atmos. Meas. Tech. Discuss.: 12 December 2014

Revised: 6 May 2015 - Accepted: 7 May 2015 - Published: 29 May 2015

\begin{abstract}
Despite their differences from more advanced and more powerful lidars, the low construction and operation cost of ceilometers (originally designed for cloud base height monitoring) has fostered their use for the quantitative study of aerosol properties. The large number of ceilometers available worldwide represents a strong motivation to investigate both the extent to which they can be used to fill in the geographical gaps between advanced lidar stations and also how their continuous data flow can be linked to existing networks of the more advanced lidars, like EARLINET (European Aerosol Research Lidar Network).

In this paper, multi-wavelength Raman lidar measurements are used to investigate the capability of ceilometers to provide reliable information about atmospheric aerosol properties through the INTERACT (INTERcomparison of Aerosol and Cloud Tracking) campaign carried out at the CNR-IMAA Atmospheric Observatory ( $760 \mathrm{~m}$ a.s.l., $40.60^{\circ} \mathrm{N}, 15.72^{\circ} \mathrm{E}$ ), in the framework of the ACTRIS (Aerosol Clouds Trace gases Research InfraStructure) FP7 project. This work is the first time that three different commercial ceilometers with an advanced Raman lidar are compared over a period of 6 months. The comparison of the attenuated backscatter coefficient profiles from a multiwavelength Raman lidar and three ceilometers (CHM15k, CS135s, CT25K) reveals differences due to the expected discrepancy in the signal to noise ratio (SNR) but also due to changes in the ambient temperature on the short and midterm stability of ceilometer calibration. Therefore, technological improvements are needed to move ceilometers to-
\end{abstract}

wards operational use in the monitoring of atmospheric aerosols in the low and free troposphere.

\section{Introduction}

For the study of climate as well as that of air pollution and its influence on health, knowledge of vertical distributions of aerosols is a key factor. From the climate point of view, information on aerosol vertical layering is required for the study of aerosol radiative forcing, aerosol-cloud interactions, and aerosol transport mechanisms. For air pollution and its impact on health, knowledge of vertical distributions and transport of aerosols located near the surface are needed in nearreal time in order to complement in situ surface measurements to give a more comprehensive understanding of population exposure. This scenario has pushed the demand for continuous aerosol measurements provided by high resolution networks of ground-based remote sensing instruments to validate and improve aerosol and pollution forecasting. In order to achieve broad, high resolution coverage, low-cost and low-maintenance instruments are needed.

Ceilometers are inexpensive instruments: their cost is typically in the EUR 12000-20000 range, except for models based on diode-pumped solid state lasers emitting at $1064 \mathrm{~nm}$ which have a cost closer to EUR 45000 . They are already deployed widely at meteorological observation stations and airports. Ceilometers are defined as single-wavelength backscatter lidars operating in the near-infrared with a pulse repetition rate on the order of a few $\mathrm{kHz}$ but with a low pulse 
energy to allow eye-safe operation. These instruments are based on the lidar principle and measure elastically backscattered returns, usually at $905-910 \mathrm{~nm}$ or $1064 \mathrm{~nm}$, and have traditionally been used only to report cloud base and vertical visibility rather than the vertical profiles of the backscatter coefficient on which they are basing these outputs. They have been also used to evaluate the cloud fraction as provided by mesoscale models (Illingworth et al., 2007). In recent years, due to their technical advances, ceilometers show great potential for aerosol applications such as volcanic ash tracking (e.g. Flentje et al., 2010; Emeis et al., 2011; Wiegner et al., 2012) and boundary layer monitoring (e.g. Tsaknakis et al., 2011).

The large number of ceilometers available worldwide (cf. http://www.dwd.de/ceilomap) represents a strong motivation to investigate the extent to which they can be used to fill the geographical gaps between advanced lidar stations within existing networks like EARLINET (European Aerosol Research Lidar Network; Pappalardo et al., 2014) and also how their continuous data flow can be linked to these networks. To fully exploit this observing capability, the E-PROFILE (http://www.eumetnet.eu/e-profile) observation program, run by the European Met Services, is developing a framework to exchange lidar backscatter data from automatic lidars and ceilometers stations across Europe.

To retrieve the vertical profile of aerosol optical properties from a ceilometer, several approaches have been proposed (e.g. O'Connor et al., 2004; Markowicz et al., 2008; Heese at al., 2010; Flentje et al., 2010; Stachlewska et al., 2010; Wiegner et al., 2012) either based on the use of ceilometer measurement only or in combination with ancillary measurements provided by a sun photometer or a nephelometer.

However, thorough characterization of ceilometer sensitivity, stability, bias and uncertainty for the observation of aerosol layers is missing and needed in order to develop the rigorous quality assurance program that will enable full exploitation of the ceilometer data.

In this paper, the outcome of the INTERACT campaign, funded and carried out in the frame of ACTRIS (Aerosol Clouds Trace gases Research InfraStructure, http://www. actris.org) transnational access activities is described. The campaign was held at CIAO, CNR-IMAA Atmospheric Observatory $\left(760 \mathrm{~m}\right.$ a.s.1., $\left.40.60^{\circ} \mathrm{N}, 15.72^{\circ} \mathrm{E}\right)$ in the period from July 2013 to January 2014 with the aim to improve understanding of ceilometer performance. This work represents the first time that three different commercial ceilometers (a picture is shown in Fig. 1) are compared with an advanced Raman lidar over a period of 6 months. To this purpose, multi-wavelength Raman lidar measurements are used to investigate the capability of ceilometers to provide reliable information about atmospheric aerosol properties. The data set used for this study has been collected at the observatory (Madonna et al., 2011) where MUSA (Multiwavelength System for Aerosol), one of the mobile reference systems used in the frame of the EARLINET Qual-

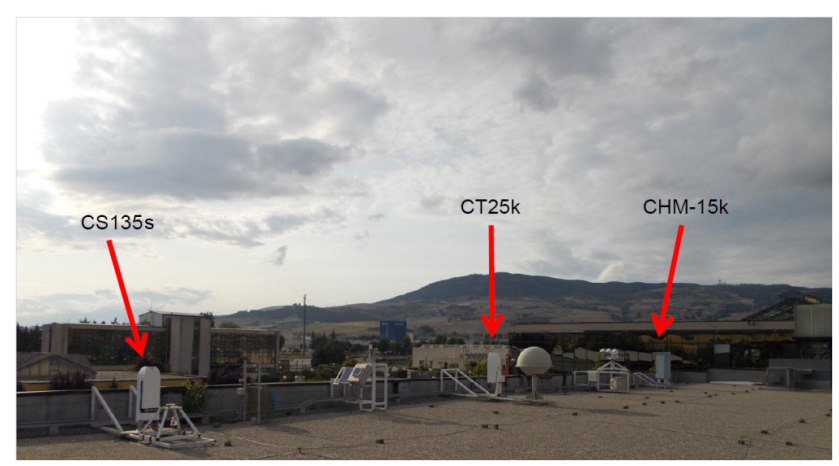

Figure 1. Ceilometer locations on CNR-IMAA Potenza observatory roof.

ity Assurance Program, is operative. $1064 \mathrm{~nm}$ MUSA attenuated backscatter coefficient profiles are compared with those provided by a CHM15k Jenoptik ceilometer operating at $1064 \mathrm{~nm}$ up to $15 \mathrm{~km}$ a.g.l. (above ground level), run at CIAO since September 2009, by a Vaisala CT25K ceilometer operating at $905 \mathrm{~nm}$ up to $7.5 \mathrm{~km}$ a.g.1., run at CIAO since 2005, and by a CS135s Campbell Scientific ceilometer prototype operating at $905 \mathrm{~nm}$ up to $10 \mathrm{~km} \mathrm{a.g.l.,} \mathrm{deployed} \mathrm{at}$ CIAO during INTERACT, provided by the manufacturer itself. Using the MUSA data products as the reference, the capability of ceilometers to detect aerosol layers and provide quantitative information about the atmospheric aerosol load is investigated.

In the next section, an overview of the INTERACT campaign, the instruments deployed during the period of the campaign, and the algorithms used for the data processing are provided. In Sect. 3, the stability of the ceilometers is discussed in comparison with the stability of the MUSA lidar. In Sect. 4, simultaneous ceilometer and lidar attenuated backscatter coefficient observations are evaluated. Summary and conclusions are finally reported in Sect. 5 .

\section{INTERACT campaign}

\subsection{Scientific objectives}

The INTERACT campaign was held at CIAO in Potenza, Italy from 1 July 2013 to 12 January 2014; the main scientific objective was to evaluate the stability, sensitivity, and uncertainties of ceilometer aerosol backscatter profiles. Three commercial ceilometers from different manufactures were compared with an advanced multi-wavelength Raman lidar, and their aerosol detection sensitivity and stability were assessed using a data set collected over a period of more than 6 months.

CIAO represents an ideal location for observations of maritime, continental and mineral aerosols observed under different weather regimes. Equally important, the observatory is equipped with further instruments, including two ad- 
vanced lidar systems, two ceilometers (CHM15k by Jenoptik and CT25K by Vaisala), a microwave radiometer, a Kaband radar, and an automated radiosonde launching system (Madonna et al., 2011). With the addition of the third ceilometer delivered to the observatory by Campbell Scientific for the campaign, CIAO had a unique opportunity to carry out an intercomparison among Raman lidar and ceilometers.

\subsection{Instruments}

MUSA is a mobile multi-wavelength lidar system based on a Nd:YAG laser equipped with second and third harmonic generators and a Cassegrain telescope with a primary mirror of $300 \mathrm{~mm}$ diameter. The three laser beams at 1064, 532 and $355 \mathrm{~nm}$ are simultaneously and coaxially transmitted into the atmosphere beside the receiver in biaxial configuration. The receiving system has 3 channels for the detection of radiation elastically backscattered from the atmosphere and 2 channels for the detection of the Raman radiation backscattered by atmospheric $\mathrm{N}_{2}$ molecules at 607 and $387 \mathrm{~nm}$. The elastic channel at $532 \mathrm{~nm}$ is split into parallel and perpendicular polarization components by means of a polarizing beam splitter cube. The backscattered radiation at all the wavelengths is acquired by photomultiplier tubes both in analog and photon counting mode. The calibration of depolarization channels is made automatically using the \pm 45 method (Freudhetnaler et al., 2009). The typical vertical resolution of the raw profiles is $3.75 \mathrm{~m}$ with a temporal resolution of $1 \mathrm{~min}$.

The MUSA system is compact and transportable. It was developed in 2009 in cooperation with the Meteorological Institute of the Ludwig-Maximilians-Universität (LMU) of Munich, and it is one of the reference systems used for the EARLINET quality assurance program (Pappalardo et al., 2014).

Ceilometers are optical instruments based on the lidar principle but eye-safe and generally lower in cost than advanced research lidars. Their primary application is the determination of cloud base height, but they are also expected to report vertical visibility for transport-related meteorology applications. Increasingly, they are expected to output attenuated backscatter coefficient profiles as well (e.g. Wiegner and Geiß, 2012) and are being trialed for aerosol mixing layer height measurement for air quality applications (e.g. Cimini et al., 2013). These instruments typically have signal to noise ratios (SNRs) considerably lower than lidar systems because of wider optical bandpass filters required to accommodate broader spectrum inexpensive diode laser sources. Eye-safety restrictions on laser power output also affect the SNR. Two of the ceilometers used in this study, the CT25k and the CS135s, are based on diode lasers while the third, the Jenoptik CHM15k, is based on narrower linewidth solid state laser technology (Nd:YAG diode-pumped laser). Compared to most of the lidar systems, ceilometers have the important advantage of being designed to be deployed unattended in the field for many years with minimal maintenance. Further information on how to discriminate a lidar, basic or advanced, from a ceilometer is provided in Wiegner et al. (2014).

Ceilometers also have several drawbacks. First of all, not all of them provide the raw backscattered signals, and their processing software tends to be a sort of "black box" for users. Ceilometer gain (or sensitivity) changes automatically depending upon backscatter and background light levels, for example from daytime to nighttime measurements or in the presence of scattered clouds. The instrument's gain can be modified by changes in the high voltage supply of the detector (an avalanche photodiode - APD), and therefore, the gain level is factored into the raw signal or the attenuated backscatter coefficient (see Eq. (3) later in the text) calculation independently for each measurement. Nevertheless, it is quite difficult to characterize different ceilometers using one parameter, such as the gain, since this might be managed in very different ways among the different types of ceilometers. Therefore, more detailed studies on the dependence of the main products delivered by a ceilometer (raw signal or attenuated backscatter coefficient) are needed.

Table 1 reports the specifications of the ceilometers used during the INTERACT campaign along with those of MUSA.

The Jenoptik CHM15k is a biaxial ceilometer based on a $1064 \mathrm{~nm} \mathrm{Nd:YAG} \mathrm{laser} \mathrm{and} \mathrm{a} \mathrm{photon} \mathrm{counting} \mathrm{avalanche}$ photodiode (APD); the instrument has a specified range of $15 \mathrm{~km}$ and full overlap at around $1500 \mathrm{~m}$ (Heese et al., 2010). Overlap correction functions are provided by the manufacturer down to approximately $500 \mathrm{~m}$. Automatic gain adjustments typically affecting Jenoptik ceilometers (Wiegner et al., 2014) are accounted for in this work and discussed later in the paper.

The Vaisala CT25K is a coaxial, common optics ceilometer based on a $905 \mathrm{~nm}$ diode laser and an analog silicon APD with a specified range of $7.5 \mathrm{~km}$ (Vaisala, 1999). According to the manual (Vaisala, 1999) the common optics configuration allows for close range onset of overlap. This common optics configuration requires additional complexity in the form of a second APD, which is needed to mitigate optical cross talk (Markowicz et al., 2008). The measurement range of the instrument is specified as $0-25000 \mathrm{ft}$ (or $7.5 \mathrm{~km}$ ), which could imply that overlap onset occurs at 0 . However this range most likely refers to sensitivity to clouds which can be detected through multiple scattering at close ranges. The instrument is well established as a tool for cloud base height measurement. Attenuated backscatter coefficient profiles are produced automatically from raw signals not available from the instrument, and the internal corrections and filtering are not specified.

The Campbell Scientific CS135s is a pre-production prototype of the recently released CS135 ceilometer. Like the CT25k, the instrument employs a $905 \mathrm{~nm}$ diode laser and an analog-mode silicon APD. However, this instrument is based 
on a divided-lens biaxial design described in Vande Hey et al. (2012). The CS135 has a range of $10 \mathrm{~km}$ (Campbell Scientific, 2014). Currently, overlap is corrected by the application of a theoretical geometric optics overlap function which has been validated by horizontal hard target measurements (see Vande Hey et al., 2011). Single-scattering overlap onset is calculated to start at $75 \mathrm{~m}$, though the instrument is sensitive to clouds from $10 \mathrm{~m}$ altitude range because of multiple scattering. Full overlap is reached at between about 300 and $400 \mathrm{~m}$.

Geometric overlap corrections for any lidar instrument become unstable as overlap approaches 0; for the INTERACT campaign, no data were evaluated below the full overlap range of MUSA which is at approximately $405 \mathrm{~m}$; therefore no overlap correction was applied to the CS135s data. "Raw" attenuated backscatter coefficient profiles were output from the CS135s. Unfortunately, the CS135s prototype suffered from an electronic distortion that affected the data. Nevertheless, the calibration of CS135s was feasible and, except for the presence of a high noise level above $3000 \mathrm{~m}$ a.g.l., data could be compared and evaluated using MUSA data, as discussed later on in the paper.

\subsection{Data processing}

This section provides an overview of the processing algorithm used to compare MUSA and ceilometer observations. MUSA data (aerosol extinction and backscatter coefficients) were processed using the automatic Single Calculus Chain (SCC) of EARLINET (Pappalardo et al., 2014; D'Amico et al., 2015). The SCC is able to pre-process lidar signals to provide aerosol optical and geometrical properties (e.g. layering) using Raman and elastic algorithms (Ansmann et al., 1992).

CHM15k data were collected using the JO-DataClient software provided by the manufacturer, while the attenuated backscatter coefficient profiles were obtained by normalizing the ceilometer range-corrected signals to the corresponding MUSA attenuated backscatter coefficient profiles. Normalization was first attempted using a region $1-2 \mathrm{~km}$ wide, located 6-7 km a.g.l. and identified as an aerosol free region from the quicklooks of the lidar measurements time series. This choice, however, tended to underestimate the normalization factor because of the very poor SNR of the ceilometer at those altitude levels. Throughout the campaign the ceilometer proved to be able to detect values of the attenuated backscatter coefficient larger than $1.0 \times 10^{-7} \mathrm{~m}^{-1} \mathrm{sr}^{-1}$ at altitude levels lower than $4 \mathrm{~km}$ a.g.l. with a vertical resolution of $30 \mathrm{~m}$ and a time resolution ranging from 45 to $120 \mathrm{~min}$. Therefore, the normalization was performed over a vertical range of $1 \mathrm{~km}$, below the altitude level where this threshold value is detected. This typically occurred around $4 \mathrm{~km}$. A detailed inspection of the normalization for each pair of MUSA and CHM15k profiles was also performed to ensure high quality of the normalization procedure.
CS135s raw signals were collected using a terminal emulator; attenuated backscatter coefficient profiles were obtained upon normalization to the corresponding MUSA attenuated backscatter coefficient profiles, using the same procedure followed for the CHM15k. Since signals in the upper troposphere were affected by electronic distortion, the normalization region selected was typically immediately below $2.0-2.5 \mathrm{~km}$ in order to have a sufficient SNR to obtain a stable normalization over the lidar profiles.

The CT25K does not provide any raw signal besides the so-called normalized sensitivity backscatter coefficient (that is proportional to the range corrected signal) output by the manufacturer's software; therefore, attenuated backscatter coefficient profiles can only be obtained using the cloud calibration technique (O'Connor et al., 2004), applied to a couple of specific cases with fully attenuating stratocumulus clouds which occurred before the beginning of the INTERACT campaign. A value of 3.37 has been obtained for the calibration constant. Indeed, in order to homogenize the analysis, the normalization of the CT25k profile on the MUSA attenuated backscatter coefficient profiles was attempted; this procedure was challenging for two reasons. First of all, due to the fact that its laser divergence is smaller than its field of view (FOV), the CT25k never reaches $100 \%$ overlap (see Table 1). Moreover, the CT25K signal often strongly decreases above 1500-2000 m. For these reasons the use of the normalization method applied to the CHM15k and the CS135s signals is problematic for the CT25K. Therefore, if from one side the use of a different calibration method might affect the homogeneity of the analysis, from the other side it ensures the use of robust methods for the calibration of each ceilometer, suitable for the different setups of the instruments considered in the intercomparison. It is worth emphasizing that even though established calibration methods applied to the outputs of manufactures' software have been shown to be robust for cloud studies (e.g. O' Connor et al., 2004), it is nonetheless highly desirable to make available raw signals from all ceilometers. This is the only way to allow the users to independently manage the whole data processing chain, to estimate the correction factors applied to the signals, and to quantify the total uncertainty budget.

All the ceilometers' attenuated backscatter coefficient profiles were compared with the lidar over a vertical resolution of $30 \mathrm{~m}$ and a time resolution ranging from 45 to $120 \mathrm{~min}$. Time and vertical resolution were selected to keep the ceilometer SNR to sufficient levels to allow for comparison to and calibration by MUSA. Only night time measurements were considered in this analysis in order to capture the best ceilometer performances and to allow the use of the roto-vibrational Raman lidar signal. An extension of the current analysis to daytime is foreseen though this will make the use of a few assumptions on the MUSA retrieval mandatory (e.g. a fixed value of lidar ratio). In addition, for the CHM15k (to avoid problems with the sudden change of the internal gain automatically selected by the ceilometer itself) only sig- 
Table 1. Specifications of the MUSA lidar at $1064 \mathrm{~nm}$ and of the three ceilometers. RFOV indicates the half-angle rectangular field of view of the instruments.

\begin{tabular}{|c|c|c|c|c|c|c|c|}
\hline Instrument & $\begin{array}{l}\text { Wavelength } \\
(\mathrm{nm})\end{array}$ & $\begin{array}{l}\text { Pulse } \\
\text { energy } \\
(\mu \mathrm{J})\end{array}$ & $\begin{array}{l}\text { Repetition } \\
\text { rate } \\
(\mathrm{kHz})\end{array}$ & Configuration & $\begin{array}{l}\text { Laser } \\
\text { divergence } \\
(\mathrm{mrad})\end{array}$ & $\begin{array}{l}\text { RFOV } \\
(\mathrm{mrad})\end{array}$ & $\begin{array}{l}\text { Approx. full } \\
\text { overlap } \\
\text { height }(\mathrm{m})\end{array}$ \\
\hline MUSA & 1064 & $5.5 \times 10^{5}$ & 0.02 & $\begin{array}{l}\text { Biaxial } \\
\left(0.3^{\circ} \text { tilt angle }\right. \\
\text { between the } \\
\text { two axes })\end{array}$ & 0.10 & 0.10 & 405 \\
\hline $\begin{array}{l}\text { Jenoptik } \\
\text { CHM15k }\end{array}$ & 1064 & 8 & $5.0-7.0$ & Biaxial & $\begin{array}{l}0.15 \\
\text { (CHM15k } \\
\text { manual) }\end{array}$ & $\begin{array}{l}0.23 \\
\text { (Wiegner } \\
\text { et al. } \\
2014 \text { ) }\end{array}$ & $\begin{array}{l}1500 \\
\text { (Heese } \\
\text { et al. } \\
2010 \text { ) }\end{array}$ \\
\hline $\begin{array}{l}\text { Vaisala } \\
\text { CT25k }\end{array}$ & $905 \pm 5 \mathrm{~nm}$ & 1.6 & 5.6 & $\begin{array}{l}\text { Coaxial } \\
\text { common } \\
\text { optics }\end{array}$ & $\begin{array}{l}0.75 \\
\text { (CT25k } \\
\text { manual) }\end{array}$ & $\begin{array}{l}0.66 \\
\text { (CT25k } \\
\text { manual) }\end{array}$ & $450-1000^{*}$ \\
\hline $\begin{array}{l}\text { Campbell } \\
\text { Sci } \\
\text { CS135s }\end{array}$ & $905 \pm 5 \mathrm{~nm}$ & 3 & 10.0 & $\begin{array}{l}\text { Split-lens } \\
\text { biaxial }\end{array}$ & 0.35 & 0.75 & $\begin{array}{l}300-400 \\
\text { (Vande Hey, } \\
2015 \text { ) }\end{array}$ \\
\hline
\end{tabular}

* Due to the fact that its laser divergence is smaller than its FOV, the CT25k never reaches $100 \%$ overlap. By the convolution calculation method described in Vande Hey et al. (2011), the instrument's optical overlap was calculated for this study from specifications in the CT25k user manual to be as follows: $45 \%$ at $100 \mathrm{~m}, 78 \%$ at $300 \mathrm{~m}, 85 \%$ at $500 \mathrm{~m}$, and reaching maximum of $90 \%$ at approximately $1000 \mathrm{~m}$, though unspecified internal corrections which determine the instrument's effective overlap could not be factored into this analysis. Markowicz et al. (2008) reported observing overlap effects of the CT25k directly from its signal to up to $450-550 \mathrm{~m}$.

nals corresponding to a value of the "base" (daylight correction factor) parameter less than 0.0015 (low background light level) were considered. The use of relative calibration (Wiegner and Geiß, 2012) can also eliminate this problem during the whole day, though this approach is not applied to the data set reported in this paper.

\section{Instrumental stability}

Ceilometer calibration is a crucial point for quantitative use of ceilometer data. Indeed the use of the Rayleigh calibration technique, based on the normalization of a raw ceilometer signal (if available) on a molecular profile, is often challenging (Binietoglou et al., 2011; Wiegner et al., 2014). Moreover, when raw ceilometer signals are not available, the use of the outputs of manufacturer software can provide large discrepancies with respect to advanced or elastic lidar profiles. Therefore, the calibration of ceilometer profiles is often mandatory.

Calibration by means of forward approaches based on colocated and coincident reference measurements is one solution to allow quantitative use of ceilometer observations; periodic re-calibration from a Raman lidar or a high-spectral resolution lidar is strongly recommended for long term calibrated use. However, the stability of the ceilometer in the periods between two calibrations needs to be checked. This type of investigation is limited if the manufacturer provides several parameters monitoring the activity of the instruments but does not provide full access to the raw signals and the processing chain.

During the INTERACT campaign, two of the ceilometers, CHM15k and CS135s prototype, provided full access to the instrument information. For both of them, the forward approach has been used, and the stability of the calibration constant (CC) has been studied in correlation with the ceilometers' parameters, while for the CT25K, the cloud calibration has been applied. $\mathrm{CC}$ is defined as the ratio between the ceilometer and the MUSA lidar signals:

$\mathrm{CC}=\frac{P_{\text {ceilo }}}{P_{\text {MUSA }}}$.

Finally, to avoid effects that any, even small but possibly relevant, misalignment of the MUSA lidar could have on the comparison, all the plots reported in this section including the MUSA attenuated backscatter coefficient were compared with the same plots obtained excluding all the data below $1000 \mathrm{~m}$ a.g.l. This height level is the typical level below which misalignments would more likely affect the MUSA signals than above. The outcome of the comparison is that no relevant differences are observed in the relationship between MUSA attenuated backscatter coefficient and ceilometer attenuated backscatter coefficient if all the values measured below $1 \mathrm{~km}$ a.g.l. are excluded. 

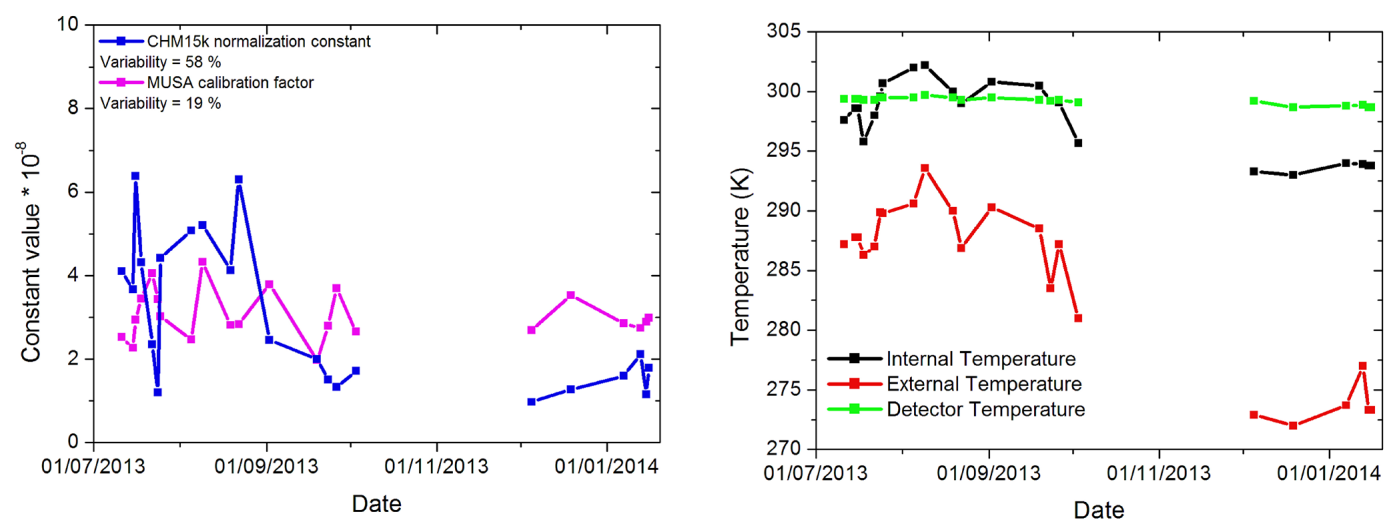

Figure 2. Left panel: the CHM15k calibration constant (blue squares) has been plotted as a function of the case number along with the lidar calibration constant (magenta squares) used for the molecular retrieval of the $1064 \mathrm{~nm}$ lidar backscatter coefficient, i.e. the constant used to normalize the lidar $1064 \mathrm{~nm}$ profile over the molecular profile; right panel: temperature of the CHM15k detector (green squares), the external (red squares) and the internal temperatures (dark squares) recorded by the instrument sensors for the cases with simultaneous measurements with MUSA. The period where no data are plotted corresponds to the an EARLINET intercomparison campaign in which MUSA was involved and moved for an intercomparison campaign in southern Italy (Wandinger et al., 2015).

\subsection{CHM15k stability}

In the left panel of Fig. 2, CC has been plotted for the selected cases along with the lidar calibration constant (CL) used for the molecular retrieval of the $1064 \mathrm{~nm}$ lidar backscatter coefficient, i.e. the constant used to normalize the $1064 \mathrm{~nm}$ lidar profile over the molecular profile. CL is defined as follows:

$\mathrm{CL}=\frac{P_{\mathrm{L}} z^{2}}{\beta T^{2}}$,

where $P_{\mathrm{L}}$ is the background-subtracted lidar signal, $\beta$ is the total backscatter coefficient including molecules and particles, and $T^{2}$ is the atmospheric transmissivity.

Analysis of CL variability allows the stability of the lidar system to be tracked. The comparison shows that the variability of CC is quite high, $58 \%$, while the variability of CL is $19 \%$. In the selected period MUSA was not available for about 1 month because it was moved for an intercomparison campaign in southern Italy (Wandinger et al., 2015), and therefore it was not available for the whole period of the campaign. After the re-installation in Potenza, the MUSA configuration underwent the realignment procedure (after 3 October 2013). However, the large variability of the CC cannot be fully attributed to the variability of MUSA. To better understand the large variability of $\mathrm{CC}$, all the system parameters recorded for each ceilometer profile have been considered. For example, in the right panel of Fig. 2, the temperature of the ceilometer detector and the external (ambient) and internal temperatures (e.g. measured in the ceilometer's housing) of the instrument are reported. The reported ambient temperature has been compared also with a co-located surface measurement of temperature obtained with a Rotronic S3 sonde. The comparison for the considered period shows the same temperature trend and a general agreement between the
Rotronic sonde and the external ceilometer temperature sensor within $1 \mathrm{~K}$ (i.e. sensor accuracy). The behavior of the internal temperature of the ceilometer appears to be well correlated with CC. The internal temperature is also well correlated with the ambient temperature. Indeed the correlation coefficient derived from a linear fitting between the ambient temperature and CC is 0.6. This could indicate that there is a non-negligible influence of the internal temperature on the instrument stability over short and mid-periods ( $\sim 6$ months) likely driven by changes in the external temperature (i.e. change of season). This indicates that thermal insulation or, more generally, the capability to have stable thermal working conditions for the ceilometer experimental setup is critical. As a consequence, at the current state of the art, the use of a forward approach to calibrate a ceilometer using lidar observations cannot be reliable over long time periods. Calibration should be frequently checked and carefully evaluated. It is also worth adding that from personal communication (by M. Wiegner, LMU, Munich, Germany, 2014), this could also be related to the unreliability in the long term of the temperature sensors of the ceilometers, which may use these temperature measurements to control system or component temperature or apply corrections, though it seems unlikely that this happened for all three deployed ceilometer systems, one of which (CS135s) was completely new and another (CHM15k) which had a completely new optical module.

Correlation with the other available system parameters such as number of laser pulses was also investigated, but nothing relevant was found. Moreover, the correlation between MUSA and CHM15k attenuated backscatter coefficient was not studied because the CHM15k is calibrated over MUSA. 


\subsection{CT25k stability}

Though limited by the lack of access to raw data, an attempt has been made to characterize the stability of CT25K. In Fig. 3, the laser temperature, the background light (though during night no significant changes are expected) and the receiver sensitivity as measured by the internal sensors of the CT25K ceilometer are reported for the cases available for comparison with MUSA. After 2 September 2013, it is possible to detect a decrease in all the parameters with respect to the corresponding average values. This corresponds to the period when the decrease of the CHM15k parameters discussed in the previous section took place, and more generally to the arrival of colder air masses over Potenza after the typical hot summertime in southern Italy. Moreover, it is also worth noting the strong correlation between the laser temperature and the background light; since these were night time observations, this could indicate that most of the noise, due to the ceilometer electronics, is provided by the laser.

In the left panel of Fig. 4, the scatterplot of the attenuated backscatter coefficient retrieved by the ceilometer CT25K observations vs. the attenuated backscatter coefficient retrieved by MUSA observations is reported; in the right panel, only the measurements performed on or after 2 September 2013 are included. The correlation coefficient for the full data set is 0.81 , but this increases to 0.90 if only the cases starting from 2 September 2013 are considered. Moreover, the left panel of Fig. 4 shows an intercept of $1.95 \times 10^{-7} \mathrm{~m}^{-1} \mathrm{sr}^{-1}$, indicating the presence of a bias at least partly affecting the data set; the bias looks strongly reduced in the right panel.

This could indicate that the retrieval of the attenuated backscatter coefficient and, in general, ceilometer measurements strongly depend on the effect of the change of season on the investigated parameters whose decrease in the mentioned period is probably related to the decrease in ambient temperature. For the CT25k, these results again indicate that ceilometer stability even over periods of weeks to months cannot be ensured, and therefore calibration constants calculated using the cloud calibration method (the standard approach for diode-based ceilometers) should be frequently checked and re-evaluated, probably on the scale of months.

The effect of water vapor on the stability of CC over time was also considered. This effect is strongly related to the presence of a water vapor absorption band at $905-910 \mathrm{~nm}$, while the effect of water vapor is limited at $1064 \mathrm{~nm}$. This effect is considered in detail in Wiegner et al. (2014), where the relative error affecting $\mathrm{CC}$ is estimated to be on the order of less than $20 \%$. For INTERACT, the correlation between the variability of the calibration constant and the variability of the integrated water vapor (IWV) content over the time was evaluated and is reported in Fig. 5. The IWV is measured by GPS receiver operational at CIAO, and the processing of CIAO GPS data is provided by the NOAA/GSD Ground-Based GPS Meteorology network. During INTER-

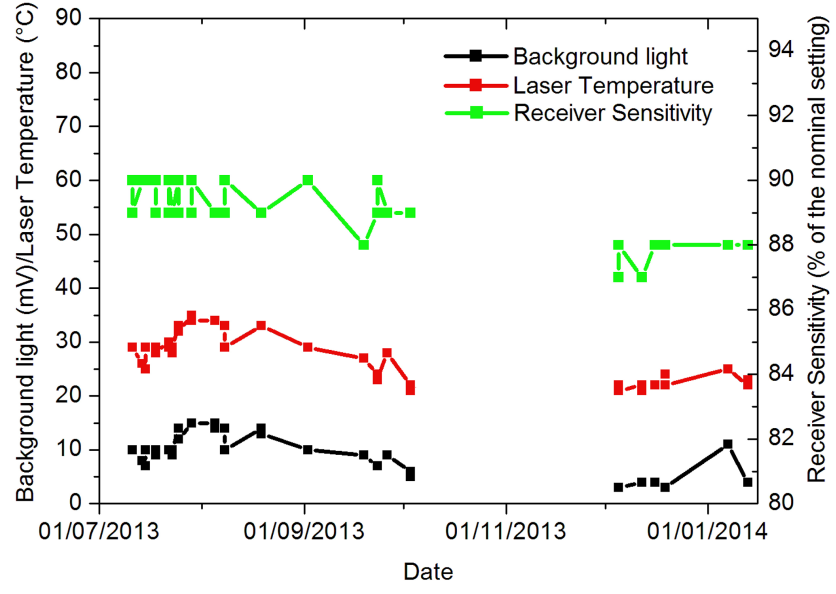

Figure 3. background light (dark squares), laser temperature (red squares), and receiver sensitivity (green squares) as measured by the internal sensors of the CT25K ceilometer are reported for the cases selected for the comparison with MUSA. The period where no data are plotted corresponds to the an EARLINET intercomparison campaign in which MUSA was involved and moved for an intercomparison campaign in southern Italy (Wandinger et al., 2015).

ACT, the time series of the IWV shows values larger than $1.0 \mathrm{~cm}$ from 1 July 2013 to 10 October 2013 with values oscillating around about $2.0 \mathrm{~cm}$. After 10 October 2013, a decrease in the IWV is observed with values oscillating around $1.25 \mathrm{~cm}$ and dipping below $1.0 \mathrm{~cm}$. Since $\mathrm{CC}$ shows a relevant change after 2 September 2013, it is possible to conclude that the effect of water vapor on the value of $\mathrm{CC}$ needs to taken into account, but variability in integrated water vapor cannot entirely justify the variability of CC observed during INTERACT.

Also for the CT25K, correlation with the other available system parameters was investigated but nothing relevant was found.

\subsection{CS135s stability}

In analogy with the investigation presented in Sect. 3.1 for the CHM15k, CC has been plotted for the CS135s in Fig. 6 . The comparison shows that the variability of $\mathrm{CC}$ is quite high, larger than $100 \%$ with a mean value of 3.25 and a standard deviation of 3.76. A few values of CC between 0 and 0.1 are also obtained, especially in summer, though they are neither related to any specific event that occurred in the atmosphere nor to an evident malfunctioning of the ceilometer. For the CS135s, CC appears to be less affected than the other ceilometers by the change of season in the environmental temperature. Nevertheless, in the period after 3 October 2013 the value of CC becomes much more unstable with peak values around 17.31, largely different from the average value of the whole series. Also in this case, though there is not a specific correlation between CC and the internal or external temperature, as for the other ceilometers, calibration 

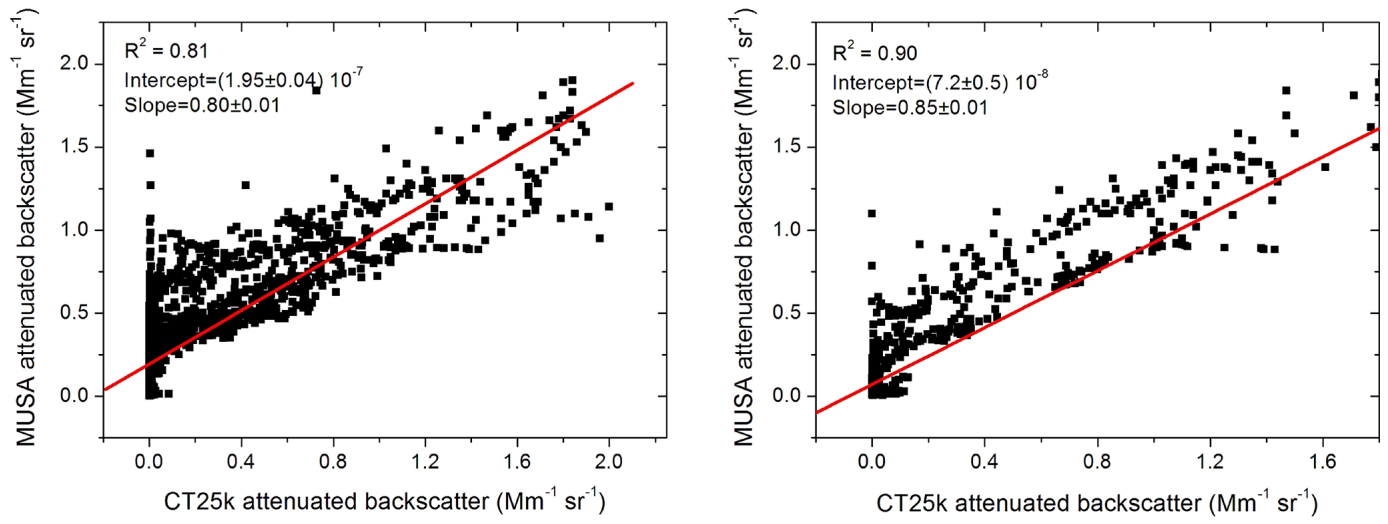

Figure 4. Scatterplot of the attenuated backscatter coefficient retrieved by the ceilometer CT25K observations vs. the attenuated backscatter coefficient retrieved by MUSA observations; the right panel shows the same plot including only cases from 2 September 2013 onwards when air temperatures were generally cooler.

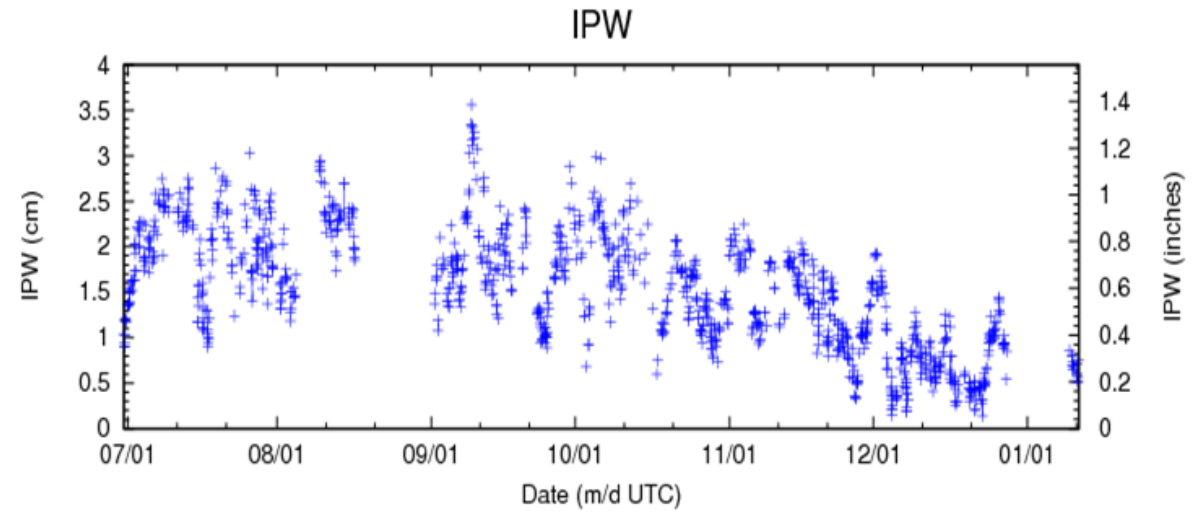

Figure 5. Time series of the integrated precipitable water (IPW) content (both in $\mathrm{cm}$ and inches) retrieved during the from $1 \mathrm{July} 2013$ to 16 January 2014 year 2013 at CIAO using the GPS technique. The processing of GPS data is provided by NOAA/GSD Ground-Based GPS Meteorology network.

might depend on the environmental temperature. Moreover, the variability of $\mathrm{CC}$ for the $\mathrm{CS} 135 \mathrm{~s}$ is much larger than for the CHM15k. This cannot be related to the distortion affecting the signals but is likely due to the general stability of the CS135s over the campaign.

For the CS135s, the period when the values of CC become much more unstable occurs in the same period when a seasonal decrease is observed in the IWV, reported in Fig. 5. However, there is not a strong correlation with the value of $\mathrm{CC}$, and this might indicate that water vapor level is only one of the effects driving the variability of CC.

Correlation with the other available system parameters was also studied for CS135s but nothing relevant was found.

\subsection{Near-range observations}

Quantitative measurements of boundary layer aerosols in the near-field region using ceilometers also depend on the stability of the overlap function with the time, on the accuracy of correction functions to be applied to ceilometer sig- nals in the incomplete overlap region, and on the reliability of the near-field measurements used to establish the correction functions. As clarified in Wiegner et al. (2014), for the retrieval of aerosol properties, incomplete overlap is not a severe issue. At typical ceilometer wavelengths and correction functions, incomplete overlap generally contributes a few percent of the uncertainty in the full overlap region. Nevertheless, overlap corrections should be applied, if available, in order to extend the investigated range closer to the instrument and improve layer retrieval closer to the surface. In order to properly characterize ceilometer (and lidar) measurement uncertainties, overlap corrections with associated confidence levels should be applied and the stability of these corrections should be tracked over time.

Typical overlap corrections range between $200-300$ and $1000 \mathrm{~m}$ among different ceilometer types. To perform an independent evaluation of the stability of the instrument in the region of incomplete overlap, an analysis of the variability of the ratio $\frac{\beta_{\text {CILIO }}^{\prime}}{\beta_{\text {MUSA }}^{\prime}}$ between the attenuated backscatter coeffi- 


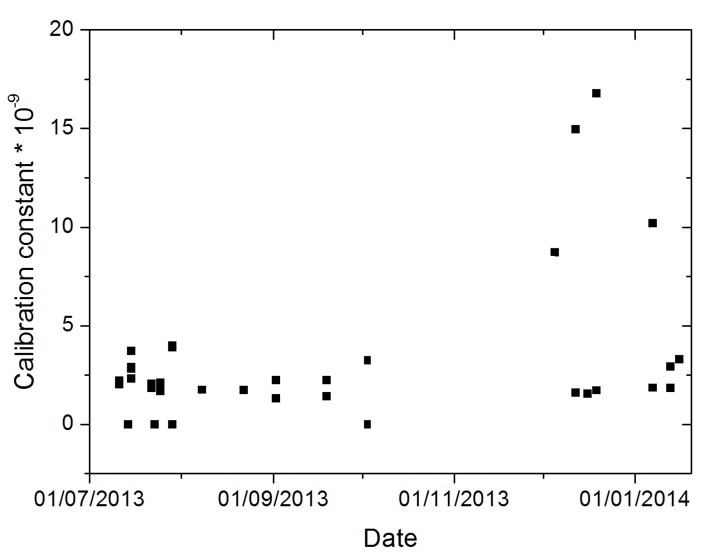

Figure 6. Variability of the calibration constant of the CS135s attenuated backscatter coefficient profiles over the corresponding MUSA profiles. The period where no data are plotted corresponds to the an EARLINET intercomparison campaign in which MUSA was involved and moved for an intercomparison campaign in southern Italy (Wandinger et al., 2015).

cient measured by each ceilometer and by MUSA should be performed; however, the variability of $\frac{\beta_{\text {CELO }}^{\prime}}{\beta_{\text {MUSA }}^{\prime}}$ is affected by differences between each ceilometer and MUSA due to the calibration of the attenuated backscatter coefficient. The mixing of these two effects (e.g. calibration and overlap) on the ceilometer signals complicates the quantitative assessment of the variability with time of the instrument performance in the region of incomplete overlap. Therefore, it is challenging to see from these data whether the overlap remains stable. Nevertheless, to provide a quantitative estimation of this stability, comparisons among measurement time series and profiles collected by the MUSA lidar and the three ceilometers are reported and discussed.

To provide an overall picture of the performance of the three ceilometers for aerosol layer profiling, we briefly report and discuss a case collected in July 2013. Figure 7 shows a comparison among the simultaneous measurement time series of attenuated backscatter coefficient retrieved with MUSA and ceilometers on 11 July 2013 from 20:42 to 22:22 UTC. The plot mainly reveals the capability of all the ceilometers to capture the structure of the residual layer; for the CHM15k and partially for the CS135s, the plot also show the capability of the ceilometers to resolve aerosol layers up to about $3 \mathrm{~km}$ a.g.l. Since the false color images cannot provide great detail on the optically thin layers observed in the free troposphere (visible in the MUSA times series), in the top panel of Fig. 8 a comparison is shown among the attenuated backscatter coefficient profiles provided by the four instruments on the same day for the signals integrated from 20:50 to 22:22 UTC. In this plot, all the profiles have been cut at the first point available from the lidar at an altitude of $405 \mathrm{~m}$ a.g.l. and the CHM15k is not corrected for the overlap function. The air mass back trajectory (not shown) revealed a continental origin for the observed layers. In the presented case, below $1.3 \mathrm{~km}$ a.g.l., i.e. in the residual layer, CHM15k and CT25K show large differences with the aerosol content identified by MUSA, while CS135s is in very good agreement.

Above the residual layer, CHM15k and CS135s show good agreement with MUSA while CT25k generally underestimates the value of the attenuated backscatter coefficient in the free troposphere due somewhat to an inaccurate calibration but more so to its typical poor SNR above $1.5 \mathrm{~km}$ a.g.l. The CHM15k and CS135s are also able to detect the aerosol observed by MUSA in the free troposphere, while the CT25k is not. It is important to keep in mind for comparisons among these instruments that the CT25K and CS135s are affected by water vapor absorption at their working wavelength $(905 \mathrm{~nm})$ where water vapor significantly suppresses laser radiation through absorption, which is not the case for the $1064 \mathrm{~nm}$ MUSA and CHM15k

In the bottom panel of Fig. 8, a second comparison between the attenuated backscatter coefficient profiles provided by the four instruments is shown, this time for 19 December 2013 in the time interval between 16:49 and 18:21 UTC. A continental origin for the layer observed with a peak around $1.5 \mathrm{~km}$ a.g.l. is acknowledged, though the particles are probably highly humidified and potentially activating droplets. Nevertheless, no forming cold or warm clouds are observed according to a cloud detection algorithm based on the gradients of the $386 \mathrm{~nm}$ MUSA Raman signals (Rosoldi et al., 2013). Below $1.5 \mathrm{~km}$ a.g.l., i.e. within the aerosol layer and below, the three ceilometers show large differences with the MUSA lidar, even larger than $50 \%$; above $1.5 \mathrm{~km}$ a.g.l. CHM15k shows a good agreement with the low aerosol content identified by MUSA, CS135s reveals a problem affecting the signal, whereas the CT25K underestimates MUSA only by $10 \%$.

The two profile comparisons in Fig. 8 provide a first estimation of the variability of the ceilometers signals with respect to the MUSA signals in the region of incomplete overlap. On 11 July, at the beginning of the campaign, the CS135s and the CT25K are in good agreement with MUSA in the region of incomplete overlap, while the CHM15k overestimates the MUSA profile; on 19 December, approaching the end of the campaign, all the ceilometers underestimate MUSA (CHM15k and CT25K up to $40 \%$, CS135s up to $80 \%$ ). This difference could be the result of a combined effect of the uncertainty due to the calibration of the ceilometer profiles and uncertainty due to ceilometer instability in the region of incomplete overlap. The latter contribution is demonstrated by the fact that the compared profiles also show different shapes and different gradients in the near range. The effect of the overlap correction on the retrieval of the aerosol backscatter coefficient (beyond the full overlap range) if using a forward approach can be easily quantified. However, it is clear that particular care should be taken in using a single overlap correction function, and its variability with the time 

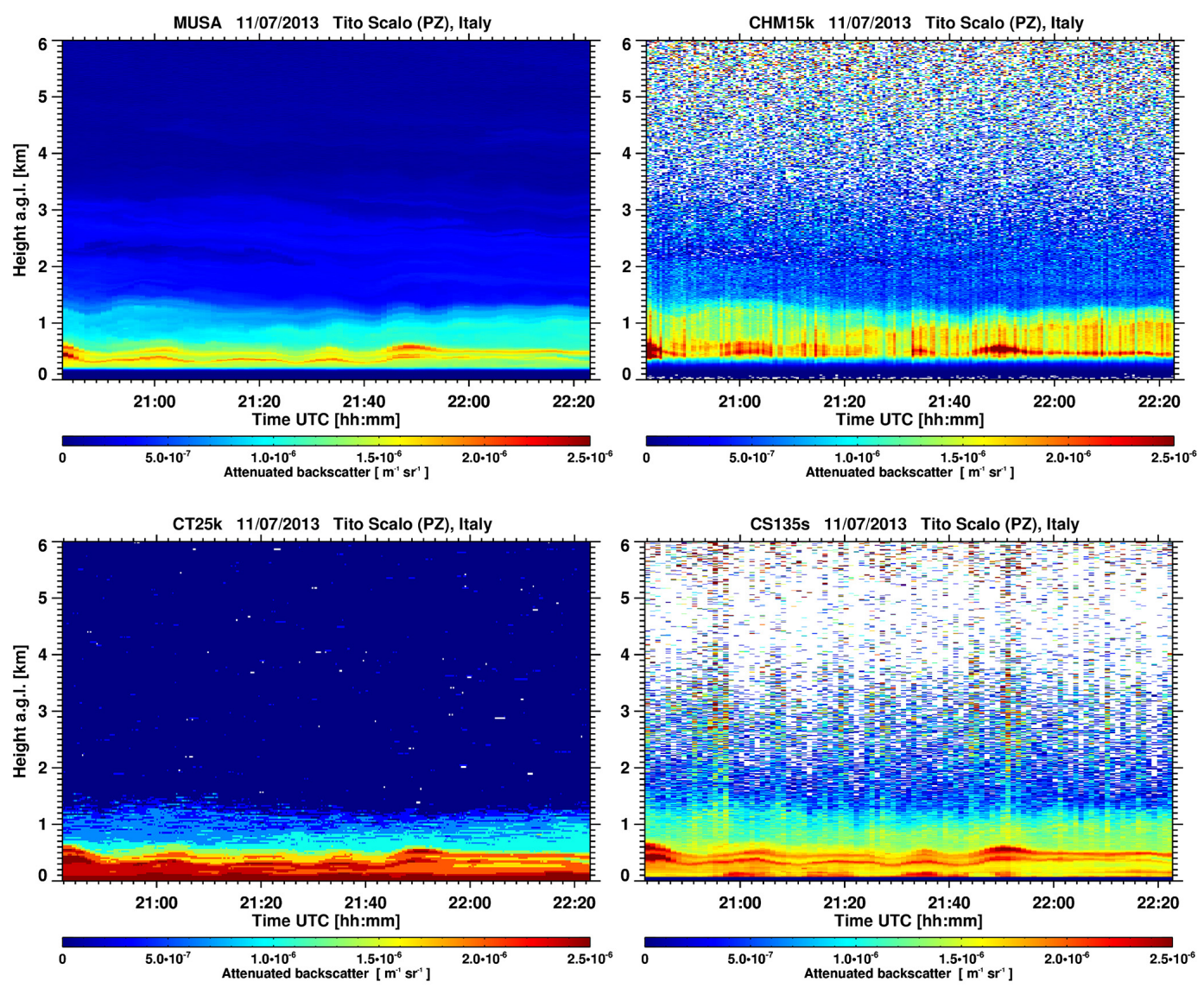

Figure 7. Observation time series of attenuated backscatter coefficient collected on 11 July 2013 from 20:42 to 22:22 UTC with MUSA and CHM15k at $1064 \mathrm{~nm}$, and with CT25K and CS135s at $905 \mathrm{~nm}$.

should be monitored. It is also important to point out that in the CHM15kx ceilometer this issue has been improved by tilting the axis of the laser toward the axis of the telescope. All the CHM15k data considered in the following to study the performance of the ceilometer in terms of attenuated backscatter coefficient were selected from $1300 \mathrm{~m}$ a.g.l. and above, in order to avoid uncertainties relating to overlap instability.

As described previously the CS135s is corrected automatically through the application of a calculated geometric optics overlap function (Vande Hey et al., 2011; Vande Hey, 2015) which places the full overlap height between 300 and $400 \mathrm{~m}$.

In the case of CT25K the output profiles are already corrected for incomplete overlap, but the function itself is unknown to the user. As shown in Table 1, the laser divergence is greater than the field of view of the instrument, so full overlap is never reached. Using a geometric optics approach similar to that described in Vande Hey et al. (2011), the parameters in the CT25K manual (Vaisala, 1999) can be used to calculate the optical overlap function of the instrument. By this method, overlap is found to be $45 \%$ at $100 \mathrm{~m}, 78 \%$ at $300 \mathrm{~m}$, and $85 \%$ at $500 \mathrm{~m}$, and it reaches maximum of $90 \%$ at approximately $1000 \mathrm{~m}$. Markowicz et al. (2008) re- ported observing overlap effects of the CT25k directly from its signal to up to $450-550 \mathrm{~m}$, starting from which point the slope of the calculated overlap function is very small. However, since the internal corrections applied in the instrument are not known, the effective overlap of the instrument can only be understood through experimental comparisons with reference instruments or horizontal measurements under stable conditions. Note that the newer Vaisala CL31 ceilometer (not available at CIAO) is described with a considerably smaller overlap region than the CT25K. However, CT25K is still one of the most widely used ceilometers in Europe, and this makes the investigation of its performance relevant for the scientific community.

\section{Comparison of lidar and ceilometer attenuated backscatter coefficient measurements}

In this section, an extensive comparison of the simultaneous ceilometer and MUSA observations is reported and discussed. As already mentioned in previous sections, the aerosol backscatter coefficient can be considered to be the only aerosol optical property that can be retrieved using a 

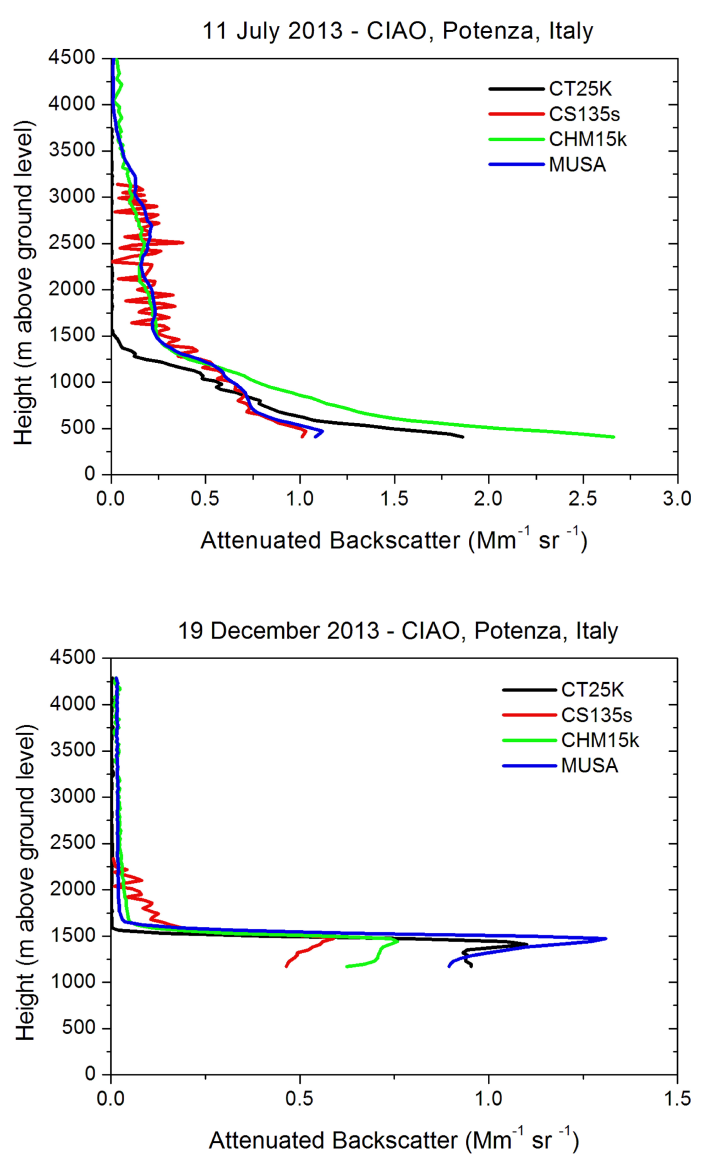

Figure 8. Comparison between the attenuated backscatter coefficient profiles provided by the four instruments (MUSA, CHM15k, CT25K, CS135s) on 11 July 2013 in the time interval between 20:50 and 22:22 UTC (upper panel), and on 19 December 2013 in the time interval between 16:49 and 18:10 UTC (lower panel). CHM15k is not corrected for the overlap function.

ceilometer. The first step towards the assessment of the feasibility of backscatter coefficient retrievals using ceilometer observations is the comparison between raw data products provided by co-located ceilometers and advanced lidars.

Unfortunately this is not possible for all ceilometers since signal processing algorithms are often proprietary. Therefore, in the following we compare the attenuated backscatter coefficient available from all the instruments, and different calibration techniques according to the availability of the raw signals. The attenuated backscatter coefficient $\beta^{\prime}$ is calculated using the Raman lidar retrieval of extinction for the MUSA lidar is defined as (Mona et al., 2009):

$\beta^{\prime}=\beta(z) T_{\mathrm{par}}^{2}(z) T_{\mathrm{mol}}^{2}(z) T_{\mathrm{H} 20}^{2}(z)$,

$\beta(z)=\beta_{\mathrm{par}}(z)+\beta_{\mathrm{mol}}(z)$,

where "par" indicates the contribution of atmospheric particulates, "mol" is for the molecule contribution and "H20" indicates the water vapor contribution at the operating wave- length. $\beta$ and $T^{2}$ are the backscatter coefficient and the transmittance, respectively. Since the $1064 \mathrm{~nm}$ wavelength is not significantly influenced by water vapor absorption as it occurs for the $905-910 \mathrm{~nm}$ band, $T_{\mathrm{H} 20}^{2}(z)$ for MUSA at $1064 \mathrm{~nm}$ has been set to 1 . Wiegner et al. (2014) have shown that, if water vapor absorption is excluded, the uncertainty in the retrieved backscatter profile should be lower than $10 \%$. This accuracy depends on both the ceilometer type and the meteorological condition.

Regarding the retrieval of the attenuated backscatter coefficient for each ceilometer, it is calibrated using the following:

a. the Cloudnet calibration scheme (O'Connor et al., 2004) for the $905-910 \mathrm{~nm}$ ceilometer by Vaisala (CT25k);

b. MUSA lidar signals as a reference for the $1064 \mathrm{~nm}$ Jenoptik ceilometer (CHM15k) and for the $905-910 \mathrm{~nm}$ Campbell ceilometer (CS135s prototype), over an integration time larger than $45 \mathrm{~min}$ and using a fixed lidar ratio of $55 \mathrm{sr}$, obtained from the local climatology of Raman lidar measurements (Mona et al., 2006).

Ceilometer attenuated backscatter coefficient profiles have been interpolated at the MUSA altitude levels. Only data above $1200 \mathrm{~m}$ a.s.l. (above sea level) have been considered. No overlap corrections have been applied because of the large variability of the overlap correction. To compare 905 and $1064 \mathrm{~nm}$ attenuated backscatter coefficient profiles, the spectral dependency of the attenuated backscatter coefficient has been considered using the backscatterrelated Angstrom exponent at $1064-532 \mathrm{~nm}$ retrieved from the MUSA measurements, assumed to be the best approximation of the 1064-905 backscatter-related Angstrom exponent. For those points of the MUSA profiles where the values of the backscatter related angstrom exponent is below 0 or exceeds the value of 2.0, the climatologic value of $1.048 \mathrm{ob}-$ tained during the period of the campaign has been assumed, consistent with previous studies. It is also assumed that in the range covered by CT25K and CS135s there were no aerosolfree regions.

\subsection{Comparison of attenuated backscatter coefficient}

In this section, a statistical comparison of the MUSA and the ceilometer attenuated backscatter coefficient is discussed. This is performed by comparing the probability density functions (pdfs) of the $\beta^{\prime}$ retrieved for the simultaneous observations performed by the four instruments. In addition, the relationship between the aerosol extinction coefficient $\left(\alpha^{\mathrm{par}}\right)$ at $355 \mathrm{~nm}$ and $\beta^{\prime}$ at $1064 \mathrm{~nm}$ obtained for MUSA is compared with the same relationship obtained considering $\beta^{\prime}$ provided by each ceilometer.

Results of this comparison are reported in Fig. 9. Left panels of Fig. 9 show the probability density functions (pdfs) of $\beta^{\prime}$ measured by MUSA and each of the ceilometers calculated for the whole INTERACT campaign from 

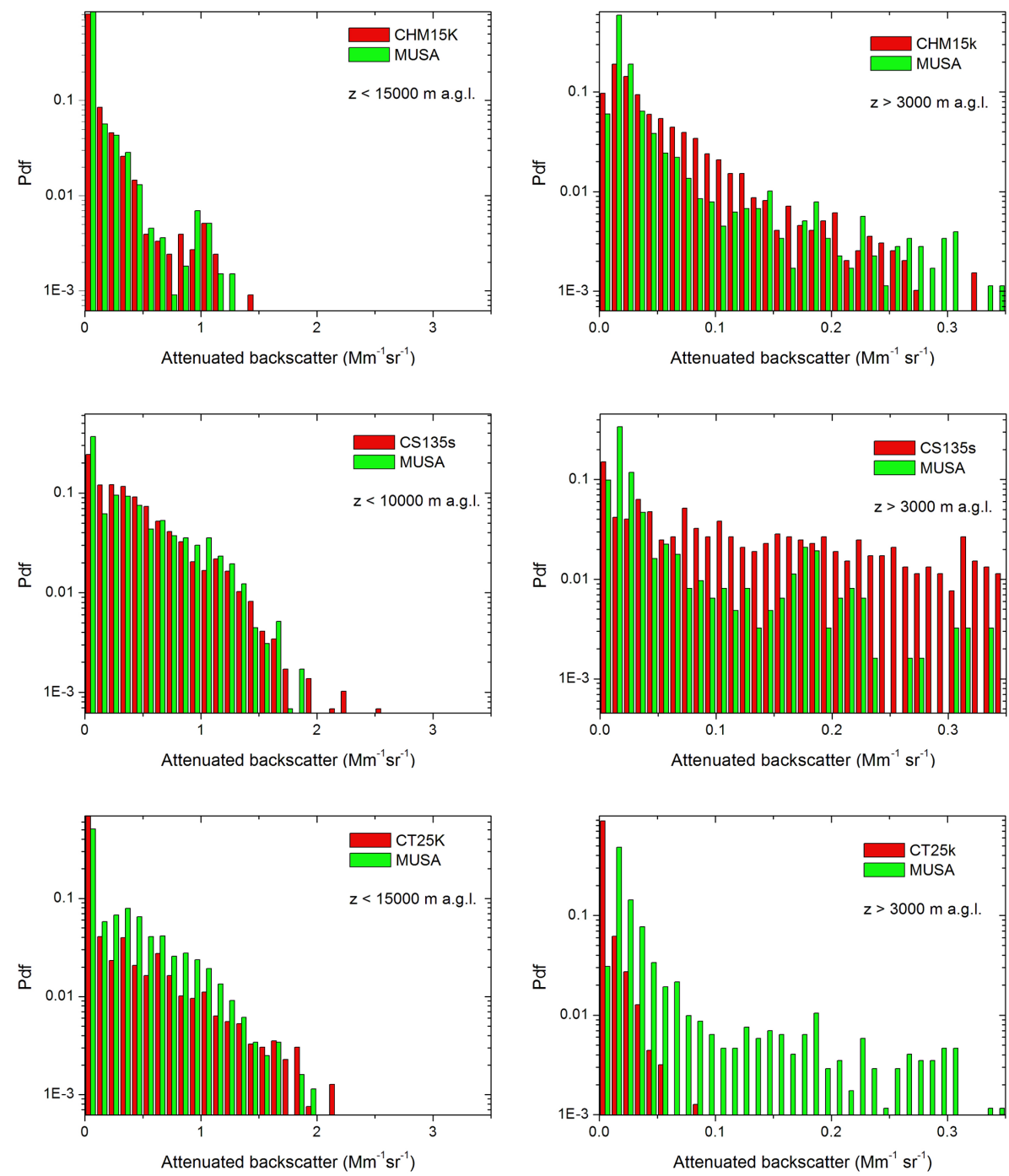

Figure 9. Probability density function of attenuated backscatter coefficient values retrieved from simultaneous observations performed by CHM15k and MUSA (upper panels), CS135s and MUSA (middle panels), CT25K and MUSA (lower panels). Left panels include all the values available from each instrument, right panels include only the values measured between above $3000 \mathrm{~m}$ a.g.l.

405 to $10000 \mathrm{~m}$ a.g.l. MUSA pdfs are considered as the truth/reference. The number of cases available for each ceilometer and MUSA simultaneously is not the same due to the use of the selection criteria described in Sects. 2 and 3 mainly affecting the CHM15k selected data. This data selection is the reason for the difference among the MUSA pdfs reported in the different panels of Fig. 9. Under ideal conditions, the pdfs of the ceilometers and MUSA should be the same. Calibration error and a low SNR can largely affect the comparison. In the case of a calibration error, the pdf could show much higher or much lower values for the ceilometer with respect to the MUSA pdf, though the effect might compensate over the whole data set. A low SNR, however, can show very high positive and very low negative values affecting, respectively, the values of the pdf higher than the maximum value observed by MUSA and values lower than $1.0 \times 10^{-10} \mathrm{~m}^{-1} \mathrm{sr}^{-1}$.

The comparison of the pdfs shows that CHM15k agrees closely with MUSA; CT25K underestimates in a more significant way the values of $\beta^{\prime}$ measured by MUSA. CS135s is in very good agreement with MUSA for values lower than $1.7 \times 10^{-6} \mathrm{~m}^{-1} \mathrm{sr}^{-1}$, but few larger values of $\beta^{\prime}$ are measured by CS135s probably because of the distortion affecting the signal. This indicates that the suppression of the electronic distortion might strongly improve the CS135s performance. Moreover, CT25K shows several very low values of $\beta^{\prime}\left(<1.0^{-10} \mathrm{~m}^{-1} \mathrm{sr}^{-1}\right)$ corresponding to much larger values of $\beta^{\prime}$ for MUSA and CHM15k. The other deviations for both the CT25K and CS135s are mainly due their lower SNR than MUSA. 

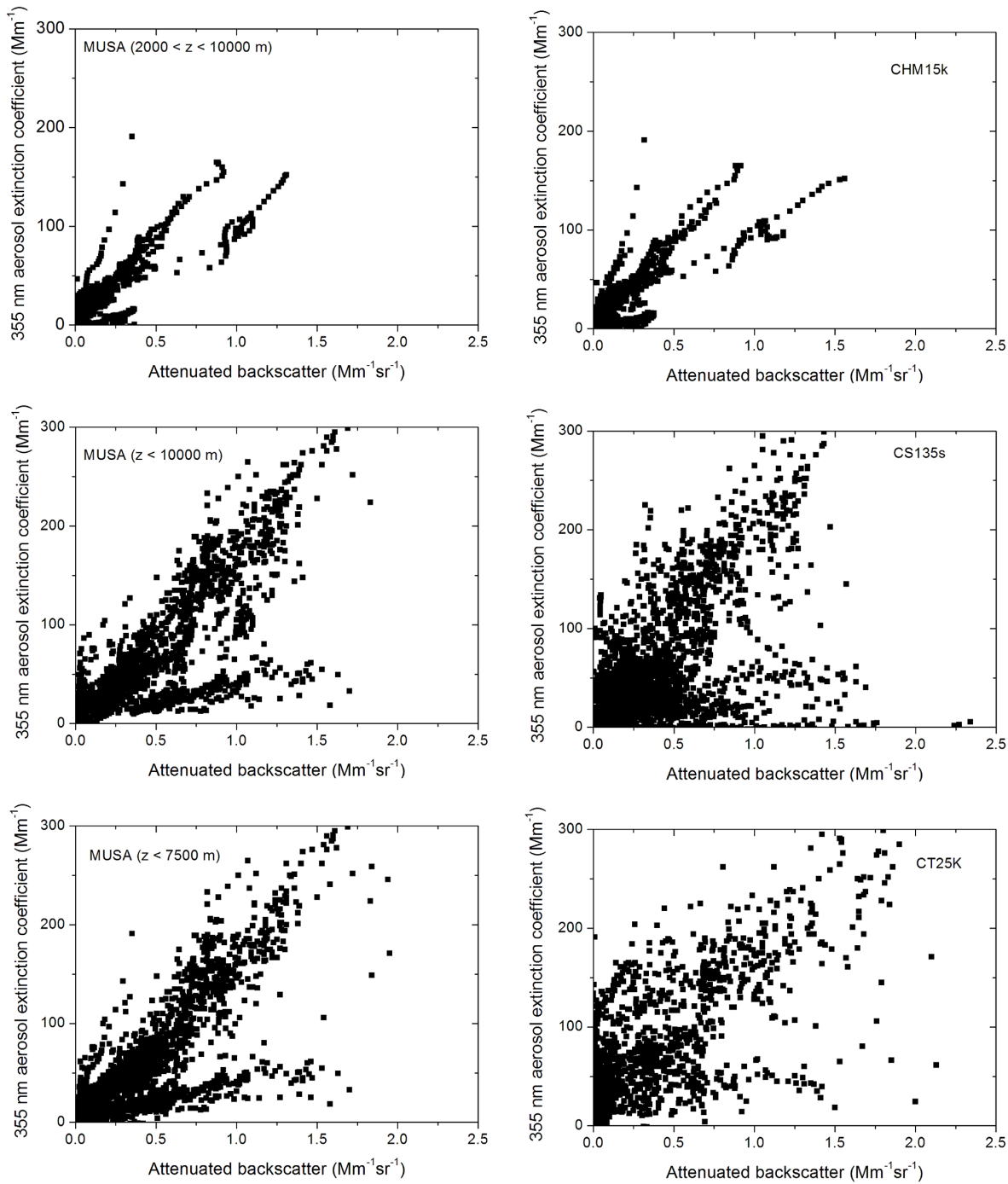

Figure 10. Scatterplot of the attenuated backscatter coefficient values retrieved from simultaneous observations performed by MUSA and CHM15k (upper panels), MUSA and CS135s (middle panels), MUSA and CT25K (lower panels) versus the $355 \mathrm{~nm}$ aerosol extinction coefficient obtained from MUSA Raman measurements. The altitude ranges reported on the left plots are due to incomplete overlap or to the range limits of each ceilometer.

The right panels of Fig. 9 show the same as the left panels but only for the altitude levels above $3000 \mathrm{~m}$. MUSA and CHM15k pdfs show good agreement, though CHM15k overestimates the values of $\beta^{\prime}$ below $1.5 \times 10^{-7} \mathrm{~m}^{-1} \mathrm{sr}^{-1}$. On the contrary, CS135s tracks MUSA to some extent for the values ranging from $0.5 \times 10^{-7} \mathrm{~m}^{-1} \mathrm{sr}^{-1}$ to $2.4 \times 10^{-7} \mathrm{~m}^{-1} \mathrm{sr}^{-1}$, but the signal distortion compromises the comparison, and CT25K looks mostly insensitive to aerosol layers above 3000 m a.g.l. This indicates that the CHM15k setup permits better performance over a larger vertical range with respect to CS135s and CT25K, which perform better in the boundary layer.

\subsection{Attenuated backscatter coefficient vs aerosol extinction coefficient}

The relationships between the $355 \mathrm{~nm}$ aerosol extinction coefficient $\left(\alpha_{355}^{\mathrm{par}}\right)$ provided by MUSA and the attenuated backscatter coefficient $\beta^{\prime}$ obtained at $1064 \mathrm{~nm}$ by MUSA and by the three ceilometers, respectively, have been compared (Fig. 10) to further investigate the ceilometers' performance and their sensitivity to different aerosol types, i.e. different extinction coefficients. While the ceilometers do not measure extinction and do not measure at $355 \mathrm{~nm}$, this comparison allows to expand the results of the pdfs analysis through the investigation of the sensitivities of ceilometers to different aerosol types whose identification is strongly related the value of the backscatter/extinction ratios. The parameter $\alpha_{355}^{\mathrm{par}}$ 
is calculated over the same time window as $\beta^{\prime}$, but at a lower effective vertical resolution (typically within $480 \mathrm{~m}$ ) in order to reduce the uncertainty and the related oscillation affecting the extinction profile calculated using the Raman lidar signal. The profile is output at $30 \mathrm{~m}$ vertical resolution to match the backscatter coefficient vertical resolution. The use of $\alpha_{355}^{\mathrm{par}}$ is due to the MUSA measurement configuration which employs an Nd:YAG laser optimized at $355 \mathrm{~nm}$ and works with the residual energy at $532 \mathrm{~nm}$; this ensures a higher SNR at $355 \mathrm{~nm}$. Similar results are expected if $\alpha_{532}^{\text {par }}$ provided by MUSA is used instead of $\alpha_{355}^{\mathrm{par}}$. In the left panels of Fig. 10, values of $\beta^{\prime}$ for the MUSA lidar are reported as a function of $\alpha_{355}^{\text {par }}$ obtained by MUSA for each single data set of simultaneous measurements with each ceilometer; in the right panels, the corresponding values of $\beta^{\prime}$ for the three ceilometers are reported as a function of $\alpha_{355}$ obtained by MUSA.

CHM15k shows a very good agreement with MUSA (the regression coefficient of the two attenuated backscatter coefficients is $R=0.95$ ), though a slightly larger dispersion than MUSA in the relationship between $\alpha_{355}^{\mathrm{par}}$ and $\beta^{\prime}$ is observed. With an increasing value of $\alpha_{355}^{\mathrm{par}}$, the difference becomes larger and the value of the $\beta^{\prime}$ is overestimated. This is particularly evident for values of $\alpha$ larger than $0.5 \times 10^{-4} \mathrm{~m}^{-1}$. Values of $\alpha$ larger than $0.5 \times 10^{-4} \mathrm{~m}^{-1}$ are mainly located in the atmospheric region below $3 \mathrm{~km}$ above the ground.

In the case of the CS135s, three clusters of data are observed: the first corresponds to values of $\beta^{\prime}$ higher than $5.0 \times 10^{-7} \mathrm{~m}^{-1} \mathrm{sr}^{-1}$ and values of $\alpha_{355}^{\mathrm{par}}$ lower than $0.5 \times 10^{-4} \mathrm{~m}^{-1} \mathrm{~V}$, where the values of $\beta^{\prime}$ are largely overestimated by the CS135s because of the signal distortion; a second cluster corresponds to values of $\beta^{\prime}$ lower than $5.0 \times 10^{-7} \mathrm{~m}^{-1} \mathrm{sr}^{-1}$ and values of $\alpha_{355}^{\mathrm{par}}$ lower than $0.5 \times 10^{-4} \mathrm{~m}^{-1}$, where the relationship looks well estimated, but the noise affecting the CS135s is much larger than MUSA; finally, a third cluster corresponding to values of $\alpha_{355}^{\mathrm{par}}$ higher than $5.0 \times 10^{-4} \mathrm{~m}^{-1}$, where a small systematic effect seems to increase the values of $\beta^{\prime}$ with respect to those measured by MUSA, which is probably related to the effect of environmental temperature, described above, on the CS135s hardware.

Finally, the scatterplot for the CT25k shows a large spreading of the points with respect to MUSA and this is due a larger noise and a decrease of the SNR. For values of $\alpha_{355}^{\mathrm{par}}$ smaller than $0.5 \times 10^{-4} \mathrm{~m}^{-1}$ (upper part of the residual layer and free troposphere) the values of $\beta^{\prime}$ are largely scattered and any consideration of the agreement with MUSA looks challenging. For values larger than $0.5 \times 10^{-4} \mathrm{~m}^{-1}$ (boundary layer and lower part of the residual layer), a systematic effect appears to increase the values of $\beta^{\prime}$ with respect to those measured by MUSA.

These results demonstrate the existence of limits on the use of ceilometer data in a quantitative way to study aerosol layers, both in the boundary layer and in the free troposphere, with performances that tend to degrade with the increase of both height and aerosol extinction coefficient. A considerable difference between MUSA and the ceilometers is expected and related to large differences in the SNR due to the power of the different laser sources used by an advanced Raman lidar and a ceilometer (see Table 1), though in this study the time resolution of the compared lidar and ceilometer profiles is typically larger than $45 \mathrm{~min}$. Nevertheless, all the plots show a difference between MUSA and ceilometers that looks proportional to the value of $\beta^{\prime}$ and $\alpha_{355}^{\mathrm{par}}$, i.e. larger values of $\beta^{\prime}$ and $\alpha$ are associated with larger discrepancies between MUSA and each ceilometer. At CIAO, higher values of aerosol optical thickness are typically observed in summer than in fall and winter (Mona et al., 2006; Boselli et al., 2012). Therefore, the sensitivity issues ceilometers face in higher aerosol optical thicknesses are compounded by the larger discrepancies between ceilometers and MUSA at higher temperatures and, for the $905 \mathrm{~nm}$ instruments, by the higher water vapor content in the summer. In particular, higher temperatures can decrease the efficiency of the ceilometer hardware and increase the bias of ceilometer attenuated backscatter coefficient profiles if calibration is not performed frequently. Other possible reasons for the differences at large values of both of $\beta^{\prime}$ and $\alpha_{355}^{\mathrm{par}}$ can be related to insufficient dynamic ranges of the systems. Along with low SNR, this may be one of the main reasons for the decreasing performance of CHM15k with increasing range into the free troposphere, shown in Fig. 9. The presence of possible cross talk might further increase the discrepancy, though this cannot be evaluated with the considered data sets.

\section{Summary and conclusions}

The INTERACT campaign carried out at the CIAO observatory in Potenza, southern Italy, aimed to evaluate ceilometer aerosol backscatter coefficient profiles using the MUSA advanced Raman lidar as a reference. Three commercial ceilometers (CMH15k, CS135s, and CT25K) from different manufactures were deployed and compared with the MUSA lidar, whose stability was also assessed.

The comparisons reveal that, in terms of an overall agreement between each ceilometer and MUSA, the experimental setup of CHM15k has the better performance. However, several limits on the use of ceilometer data in a quantitative way to study aerosol layers were also observed.

The main findings of the investigation are described in the following points.

1. Though they are manufactured in a very robust way and look very rugged, ceilometers are quite sensitive to the large changes in external temperature and collected background levels that occur on daily or seasonal bases; this generates adjustments of system parameters that affect the stability of sensor response over time. In particular, CHM15K ceilometer calibrated through 
normalization to MUSA lidar profiles show a variability of $58 \%$ versus a variability of the MUSA lidar within $19 \%$. The ambient temperature shows a correlation coefficient of 0.6 with the normalization factor of the CHM15k. This could indicate that there is a non-negligible influence of the internal temperature on the instrument stability over short and mid-periods ( $\sim 6$ months) likely driven by changes in external temperature (i.e. change of season). This indicates that thermal insulation or, more generally, the capability to have stable thermal working conditions for the ceilometer experimental setup is critical. It is worth mentioning that this could also be related to problems with the internal temperature sensors of the ceilometers and resulting temperature control or temperature correction errors, though for INTERACT it seems unlikely that this happened for three different systems. Manufacturers should do their best to make changes of settings traceable and to quantify the related effects on the signals. Finally, the use of a forward approach to calibrate a ceilometer using lidar observations or the use of a different calibration method should be frequently re-evaluated and checked.

2. The effect of water vapor on the stability of $\mathrm{CC}$ over time has also been evaluated. This effect is nontrivial for ceilometers working at $905-910 \mathrm{~nm}$, while for $1064 \mathrm{~nm}$ instruments the effect of water vapor is minimal. The correlation between the variability of $\mathrm{CC}$ and the variability of the IWV reveals the occurrence of drier conditions in the period when a relevant change of $\mathrm{CC}$ is observed for both the CT25K and the CS135s, though water vapor absorption cannot entirely justify the variability of CC observed during INTERACT, and it appears to be only one of the effects driving the variability of CC.

3. Two specific comparisons between MUSA and the three ceilometers profiles have been performed to investigate ceilometer performance in the region of incomplete overlap. In this region, ceilometers may have large deviations from MUSA profiles with performances likely due to a combined effect of the uncertainty due to the calibration of the ceilometer profiles and the uncertainty due to the ceilometer instability in the region of incomplete overlap. This also suggests that the performances of the ceilometers in the near range need to be monitored over time.

4. Comparison of the pdfs of the four instruments shows that CHM15k agrees closely with MUSA, CT25K underestimates in a more significant way the values of $\beta^{\prime}$ measured by MUSA, while CS135s is in very good agreement with MUSA for values lower than $1.7 \times 10^{-6} \mathrm{~m}^{-1} \mathrm{sr}^{-1}$. A more efficient suppression of the electronic noise in the CS135s might improve its performance. For the altitude levels above $3000 \mathrm{~m}$, only MUSA and CHM15k show a good agreement, while CS135s tracks MUSA to some extent.

5. Differences among MUSA and the ceilometers appear to be proportional to the values of $\beta^{\prime}$ and $\alpha_{355}^{\mathrm{par}}$, i.e. larger values of $\beta^{\prime}$ and $\alpha_{355}^{\mathrm{par}}$ are associated with larger discrepancies between MUSA and each ceilometer. Larger values of $\beta^{\prime}$ and $\alpha_{355}^{\mathrm{par}}$ are associated with summer and with the increase of surface temperature; this suggests a possible correlation between temperature-sensitive instrument parameters of the ceilometers and the larger discrepancies observed during the warmer season. Moreover, differences at large values of both of $\beta^{\prime}$ and $\alpha$ are also probably related to limitations in dynamic range of the systems.

In conclusion, ceilometers show a good potential for aerosol profiling, but they are limited. They have shown promising capabilities in the detection of aerosol plumes in synergy with lidars and/or transport/chemical models (Emeis et al., 2011). Differences among MUSA and the ceilometers are certainly expected given the large differences in SNR due to the different laser sources used by an advanced lidar and a ceilometer, but further technological improvements of ceilometers should be pursued in order to unlock their potential for operational use in the monitoring of atmospheric aerosols. An extension of the current analysis to daytime is foreseen, and an investigation of historical data from CT25K and CHM15k has been planned to confirm or refine the outcome of the INTERACT campaign.

Acknowledgements. The authors are gratefully to Matthias Wiegner for his crucial comments. The financial support for EARLINET by the European Union under grant RICA 025991 in the Sixth Framework Programme is gratefully acknowledged. Since 2011 EARLINET is integrated in the ACTRIS Research Infrastructure Project supported by the European Union Seventh Framework Programme (FP7/2007-2013) under grant agreement n. 262254. The authors would also like to thank Campbell Scientific, Ltd. for contributing the CS135s for this campaign.

Edited by: A. Ansmann

\section{References}

Ansmann, A., Wandinger, U., Riebesell, M., Weitkamp, C., and Michaelis, W.: Independent measurement of extinction and backscatter profiles in cirrus clouds by using a combined Raman elastic-backscatter lidar, Appl. Optics, 31, 7113-7131, 1992.

Binietoglou, I., Amodeo, A., D’Amico, G., Giunta, A., Madonna, F., Mona, L., and Pappalardo, G.: Examination of possible synergy between lidar and ceilometer for the monitoring of atmospheric aerosols, in: Lidar Technologies, Techniques, and Measurements for Atmospheric Remote Sensing VII, Vol. 8182, 
edited by: Singh, U. N., Gelsomina Pappalardo, Proc. SPIE, Bellingham, USA, doi:10.1117/12.897530, 2011.

Boselli, A., Caggiano, R., Cornacchia, C., Madonna, F., Mona, L., Macchiato, M., Pappalardo, G., and Trippetta, S.: Multi year sun-photometer measurements for aerosol characterization in a Central Mediterranean site, Atmos. Res., 104-105, 98-110, doi:10.1016/j.atmosres.2011.08.002, 2012.

Campbell Scientific, Ltd.: CS135 Ceilometer User Guide, CSL 950, 14 March 2014, https://s.campbellsci.com/documents/ eu/manuals/cs135.pdf (last access: 26 May 2015), 2014.

Cimini, D., De Angelis, F., Dupont, J.-C., Pal, S., and Haeffelin, M.: Mixing layer height retrievals by multichannel microwave radiometer observations, Atmos. Meas. Tech., 6, 2941-2951, doi:10.5194/amt-6-2941-2013, 2013.

D’Amico, G., Amodeo, A., Baars, H., Binietoglou, I., Freudenthaler, V., Mattis, I., Wandinger, U., and Pappalardo, G.: EARLINET Single Calculus Chain - general presentation methodology and strategy, Atmos. Meas. Tech. Discuss., 8, 4973-5023, doi:10.5194/amtd-8-4973-2015, 2015.

Emeis, S., Forkel, R., Junkermann, W., Schäfer, K., Flentje, H., Gilge, S., Fricke, W., Wiegner, M., Freudenthaler, V., Groß, S., Ries, L., Meinhardt, F., Birmili, W., Münkel, C., Obleitner, F., and Suppan, P.: Spatial structure and dispersion of the April 16/17, 2010 volcanic ash cloud over Germany, Atmos. Chem. Phys., 11, 2689-2701, doi:10.5194/acp-11-2689-2011, 2011.

Flentje, H., Claude, H., Elste, T., Gilge, S., Köhler, U., PlassDülmer, C., Steinbrecht, W., Thomas, W., Werner, A., and Fricke, W.: The Eyjafjallajökull eruption in April 2010 - detection of volcanic plume using in-situ measurements, ozone sondes and lidar-ceilometer profiles, Atmos. Chem. Phys., 10, 10085-10092, doi:10.5194/acp-10-10085-2010, 2010.

Freudenthaler, V., Esselborn, M., Wiegner, M., Heese, B., Tesche, M., Ansmann, A., Müller, D., Althausen, D., Wirth, M., Fix, A., Ehret, G., Knippertz, P., Toledano, C., Gasteiger, J., Garhammar, M., and Seefeldner, M.: Depolarization ratio profiling at several wavelengths in pure Saharan dust during SAMUM 2006, Tellus B, 61, 165-179, doi:10.1111/j.1600-0889.2008.00396.x, 2009 ,

Heese, B., Flentje, H., Althausen, D., Ansmann, A., and Frey, S.: Ceilometer lidar comparison: backscatter coefficient retrieval and signal-to-noise ratio determination, Atmos. Meas. Tech., 3, 1763-1770, doi:10.5194/amt-3-1763-2010, 2010.

Illingworth, A. J., Hogan, R. J., O’Connor, E. J., Bouniol, D., Brooks, M. E., Delanoe, J., Donovan, D. P., Gaussiat, N., Goddard, J. W. F., Haeffelin, M., Klein Baltink, H., Krasnov, O. A., Pelon, J., Piriou, J. M., and van Zadelhoff, G. J.: Cloudnet: Continuous evaluation of cloud profiles in seven operational models using ground-based observations, B. Am. Meteorol. Soc., 88, 883-898, 2007.

Madonna, F., Amodeo, A., Boselli, A., Cornacchia, C., Cuomo, V., D'Amico, G., Giunta, A., Mona, L., and Pappalardo, G.: CIAO: the CNR-IMAA advanced observatory for atmospheric research, Atmos. Meas. Tech., 4, 1191-1208, doi:10.5194/amt4-1191-2011, 2011.

Markowicz, K. M., Flatau, P. J., Kardas, A. E., Remiszewska, J., Stelmaszczyk, K., and Woeste, L.: Ceilometer retrieval of the boundary layer vertical aerosol extinction structure, J. Atmos. Ocean. Tech., 25, 928-944, 2008.
Mona, L., Amodeo, A., Pandolfi, M., and Pappalardo, G.: Saharan dust intrusions in the Mediterranean area: Three years of Raman lidar measurements, J. Geophys. Res., 111, D16203, doi:10.1029/2005JD006569, 2006.

Mona, L., Pappalardo, G., Amodeo, A., D’Amico, G., Madonna, F., Boselli, A., Giunta, A., Russo, F., and Cuomo, V.: One year of CNR-IMAA multi-wavelength Raman lidar measurements in coincidence with CALIPSO overpasses: Level 1 products comparison, Atmos. Chem. Phys., 9, 7213-7228, doi:10.5194/acp-97213-2009, 2009.

O'Connor, E. J., Illingworth, A. J., and Hogan, R. J.: A technique for autocalibration of cloud lidar, J. Atmos. Ocean. Tech., 21, 777-786, 2004.

Pappalardo, G., Amodeo, A., Apituley, A., Comeron, A., Freudenthaler, V., Linné, H., Ansmann, A., Bösenberg, J., D’Amico, G., Mattis, I., Mona, L., Wandinger, U., Amiridis, V., AladosArboledas, L., Nicolae, D., and Wiegner, M.: EARLINET: towards an advanced sustainable European aerosol lidar network, Atmos. Meas. Tech., 7, 2389-2409, doi:10.5194/amt-7-23892014, 2014.

Rosoldi, M., Claramunt, P. G., Madonna, F., Amodeo, A., Binietoglou, I., D’Amico, G., Giunta, A., Mona, L., Papagiannopoulos, N., and Pappalardo, G.: Study of thin clouds at CNR-IMAA Atmospheric Observatory (CIAO), Ann. Geophys., 56, 6337, doi:10.4401/ag-6337, 2013.

Stachlewska, I. S., Markowicz, K. M., and Piadlowski, M.: On forward Klett's inversion of ceilometer signals, Proc. 25th ILRC International Laser Radar Conference, 5-9 July 2010, St. Petersburg, Russia, 1154-1157, 2010.

Tsaknakis, G., Papayannis, A., Kokkalis, P., Amiridis, V., Kambezidis, H. D., Mamouri, R. E., Georgoussis, G., and Avdikos, G.: Inter-comparison of lidar and ceilometer retrievals for aerosol and Planetary Boundary Layer profiling over Athens, Greece, Atmos. Meas. Tech., 4, 1261-1273, doi:10.5194/amt-4-1261-2011, 2011.

Vaisala Oyj: Ceilometer CT25K User's Guide, CT25K-U059en-2.1, 26 February 1999.

Vande Hey, J.: A Novel Lidar Ceilometer: Design, Implementation and Characterisation, Springer Theses, Springer International Publishing, Switzerland, 2015.

Vande Hey, J., Coupland, J., Foo, M., Richards, J., and Sandford, A.: Determination of overlap in lidar systems, Appl. Optics, 50, 5791-5797, 2011.

Vande Hey, J., Coupland, J., Richards, J., and Sandford, A.: Design and implementation of a divided-lens lidar ceilometer prototype for manufacture, IEEE International Geoscience and Remote Sensing Symposium (IGARSS), 22-27 July 2012, Munich, 5002-5005, 2012.

Wandinger, U., Freudenthaler, V., Baars, H., Amodeo, A., Engelmann, R., Mattis, I., Groß, S., Pappalardo, G., Giunta, A., D’Amico, G., Chaikovsky, A., Osipenko, F., Slesar, A., Nicolae, D., Belegante, L., Talianu, C., Serikov, I., Linné, H., Jansen, F., Apituley, A., Wilson, K., de Graaf, M., Trickl, T., Giehl, H., Adam, M., Comeron, A., Rocadenbosch, F., Sicard, M., Pujadas, M., Molero, F., Alados-Arboledas, L., Preißler, J., Wagner, F., Pereira, S., Lahnor, B., Gausa, M., Grigorev, I., Stoyanov, D., Iarlori, M., and Rizi, V.: EARLINET instrument intercomparison campaigns: overview on strategy and results, Atmos. Meas. Tech. Discuss., in preparation, 2015. 
Wiegner, M. and Geiß, A.: Aerosol profiling with the Jenoptik ceilometer CHM15kx, Atmos. Meas. Tech., 5, 1953-1964, doi:10.5194/amt-5-1953-2012, 2012.

Wiegner, M., Madonna, F., Binietoglou, I., Forkel, R., Gasteiger, J., Geiß, A., Pappalardo, G., Schäfer, K., and Thomas, W.: What is the benefit of ceilometers for aerosol remote sensing? An answer from EARLINET, Atmos. Meas. Tech., 7, 1979-1997, doi:10.5194/amt-7-1979-2014, 2014.
Wiegner, M., Gasteiger, J., Groß, S., Schnell, F., Freudenthaler, V., and Forkel, R.: Characterization of the Eyjafjallajökull ashplume: Potential of lidar remote sensing, Phys. Chem. Earth, 4546, 79-86, doi:10.1016/j.pce.2011.01.006, 2012. 